\title{
Clarity of Solution
}

National Cancer Institute

\section{Source}

National Cancer Institute. Clarity of Solution. NCI Thesaurus. Code C134261.

Measurement of the turbidity of the solution. 